\title{
¿Cuánto vale la vida de mi hijo? Una aproximación a las formas de politización de muertes de jóvenes producidas por la policía en la ciudad de Rosario, Argentina, a partir del caso Jonatan Herrera
}

How much my son's life is worth? An approach to different forms of politization of young people deaths produced by the police in the city of Rosario-Argentina, from the case of Jonatan Herrera

Quanto vale a vida do meu filho? Uma aproximação às formas de politização de mortes de jovens produzidas por policiais na cidade de Rosário, Argentina, a partir do caso Jonatan Herrera

\section{Eugenia Cozzi}

Argentina. Universidad Nacional de Rosario. Profesora de la Facultad de Derecho, Universidad Nacional de Rosario (UNR). Becaria Posdoctoral de Consejo Nacional de Investigaciones Científicas y Técnicas (CONICET). Investigadora del Equipo de Antropología Política y Jurídica, Sección Antropología Social del Instituto de Ciencias Antropológicas, Facultad de Filosofía y Letras, Universidad de Buenos Aires (UBA). Doctora en Antropología; Universidad de Buenos Aires (UBA). ID ORCID: https://orcid.org/0000-0002-9108-5905. E-mail: eugecozzi@gmail.com. Colaboração: pesquisa bibliográfica, pesquisa empírica, análise de dados, redação.

\section{Marilé Di Filippo}

Argentina. Universidad Nacional de Rosario. Profesora - grado y posgrado - en la Universidad Nacional de Rosario (UNR). Investigadora del Instituto de Investigaciones de la Facultad de Ciencia Política y RR. II. (UNR), del Centro de Estudios Interdisciplinarios (UNR) y del equipo "Arte, cultura y política en la Argentina reciente” del Instituto de Investigaciones Gino Germani, (UBA). ID ORCID: https://orcid.org/0000-0003-1868-2348.E-mail: mariledifilippo@gmail.com. Colaboração:pesquisa bibliográfica, pesquisa empírica, análise de dados, redação.

Recebido em 03 de junho de 2019

Avaliador A: 17 de junho de 2019

Avaliador B: 25 de junho de 2019

Aceito em 25 de julho de 2019 


\section{Resumen}

El artículo analiza formas de politización de la muerte de jóvenes asesinados por la policía, a partir de la reconstrucción de una intervención teatral que integró el repertorio de protesta con motivo de la muerte de Jonatan Herrera por parte de policías de la provincia de Santa Fe, Argentina; hecho que resultó en un "caso paradigmático". Dicha intervención teatral fue realizada por familiares, amigos y amigas del joven junto a artistas locales, activistas y militantes de distintas organizaciones sociales, y se diseñó en torno a tres preguntas: ¿Quién era Jonatan Herrera?, ¿cómo lo mataron? y ¿cómo fue el proceso de búsqueda de justicia? Interesa detenerse en esta intervención, por un lado, porque fue una acción que procuró de manera novedosa denunciar, limitar y/o resistir el uso de la fuerza policial, además de permitir indagar prácticas, sentidos y valores asociados a las luchas por la justicia; por otro lado, porque constituyó una intervención significativa dentro de las estéticas de la protesta social en casos de "violencia policial" en esta ciudad. Se sostiene que dicha intervención se constituyó en una instancia relevante de politización de la muerte, en tanto significó una forma de reasignación de humanidad al joven asesinado, a partir de la recomposición de su biografía mientras vida digna de ser vivida; porque implicó una forma de construcción de verdad y justicia, que excedió la arena jurídica y, por lo tanto, supuso una intensa y creativa implicación corporal por parte de sus familiares, amigos y amigas.

Palabras clave: Policía, Muerte, Activismo, Justicia.

\section{Abstract}

This article analyzes different forms of death politicization of young people murdered by the police, with use of the reconstruction of a theatrical intervention that integrates the protest repertoire of Jonatan Herrera's death produced by police forces of Santa Fe, Argentina, which resulted in a "paradigmatic case". This theatrical intervention was performed by Jonatan's family and friends, local artists, activists and members from different organizations. It was designed around three questions: Who was Jonatan Herrera? How was he killed? What was the process of searching for justice? On the one hand, this case attains significance since it questioned practices, meanings and values associated with the fight for justice by condemning, limiting and/or resisting the use of police force in a creative manner, and on the other, insofar as it lies within the aesthetics of social protest in cases of "police violence" in this city. We argue that the intervention was established 
during a pertinent instance of death politicization, as it functions as a form of reassigning humanity to murdered young men through the reconstruction of his biography as a life worthy to be lived. It was a kind of truth- and justice-building that exceeded the legal field as it pressuposes an intense and creative phisical involvement of his family and friends.

Keywords: Police, Death, Activism, Justice.

\section{Resumo}

O artigo analisa as formas de politização da morte de jovens assassinados pela polícia, partindo da reconstrução de uma intervenção teatral que integrou o repertório de protesto por ocasião da morte de Jonatan Herrera por parte de policiais da província de Santa Fé, na Argentina; fato que foi produzido como um "caso paradigmático". Tal intervenção foi realizada por parentes, amigos e amigas com artistas locais, ativistas e militantes de diversas organizações sociais, e foram projetadas acerca de três perguntas: quem foi Jonatan Herrera? Como ele foi morto? Como foi o processo de demanda por justiça? Interessa analisar esta intervenção, por um lado, porque foi uma ação que buscou denunciar, limitar e/ou resistir ao uso da força policial de forma criativa e, por isso, indagar sobre práticas, sentidos e valores associados com a luta por justiça. Por outro lado, porque ela foi uma intervenção significativa dentro da estética do protesto social em casos de "violência policial" nessa cidade. Argumenta-se que tal intervenção tenha constituído um caso relevante de politização da morte, pois significou uma maneira de devolver a humanidade ao jovem assassinado, a partir da recomposição de sua biografia como uma vida digna de ser vivida; porque implicou uma forma de construção de verdade e da justiça que ultrapassava a arena legal, portanto supunha uma implicação corporal intensa e criativa por parte de seus familiares, amigos e amigas.

Palavras-chave: Polícia, Morte, Ativismo, Justiça.

\section{INTRODUCCIÓN}

Una mañana del mes de agosto del año 2017 -hacía más de dos años que policías del Comando Radioeléctrico (CRE) y de la Policía de Acción 
Táctica (PAT), áreas de la policía santafesina ${ }^{1}$, habían matado al joven Jonatan Herrera- estábamos junto a sus familiares en tribunales provinciales esperando la resolución del tribunal de segunda instancia que revisó las condenas dictadas meses atrás a cuatro policías. Condenas que habían sido reprochadas y repudiadas tanto por familiares, amigos/as, allegados/as del joven muerto, como por la querella y demás organizaciones que acompañaron el pedido de justicia, por considerar que se trataba de penas insuficientes frente a la gravedad de lo ocurrido. Familiares, amigos/as, abogados/as querellantes, activistas y militantes esperaban expectantes que el juez y las juezas que integraron el tribunal de segunda instancia decidieran aumentar las penas.

Sin embargo, no fue eso lo ocurrió esa mañana. El tribunal no sólo no aumentó las penas de los policías condenados, sino que en relación a tres de ellos decidió rebajar el tiempo de encierro. En la sala de audiencia la respuesta de sus familiares fue inmediata. Con aplausos que denunciaban una especie de burla o farsa de quienes deberían impartir "justicia" y condenar "adecuadamente" a los policías, seguidos de gritos y llantos manifestaron su enojo. Rápidamente fueron desalojados/as de la sala por la policía y llevados/as hacia uno de los pasillos del edificio de tribunales, donde permanecieron unos minutos. Activistas, militantes, familiares, amigos/as y allegados/as intentaban consolar a los familiares más próximos que lloraban y gritaban. Periodistas trataban de recoger algún testimonio para la que sería la noticia del día en las páginas policiales de los diarios locales.

Decidieron, entonces, salir del edificio de tribunales y reunirse en la puerta donde esperaban otros/as integrantes de organizaciones sociales que habían ido a acompañar a la familia. María Elena, la mamá de Jonatan, en la escalinata del tribunal, lloraba de manera desconsolada, se quejaba de la reducción de la condena, de la morigeración estatal de la gravedad de lo sucedido y (se) preguntaba una y otra vez, “¿cómo puede ser?, ¿cuánto vale la vida de mi hijo?”. De algún modo,

\footnotetext{
En Argentina, dado su carácter federal, cada ejecutivo provincial organiza su propia fuerza de seguridad; en nuestro caso, se trata de la policía de la provincia de Santa Fe (BARRERA, 2013). El CRE depende de la Agrupación Cuerpo de esa policía, cumple funciones de investigación y prevención: tiene como principal tarea el patrullaje en la vía pública (BIANCIOTTO, 2014). La PAT se creó en el año 2015, en un contexto crítico en materia de seguridad en la provincia, se puso en funcionamiento con escasa formación y entrenamiento; fue diseñada como una fuerza de "choque" para abordar lo que se caracterizó como "criminalidad compleja" e intervenir en zonas consideradas "peligrosas" (CELS/UNR, 2017).
} 
esa reducción de la condena era leída e interpretada por la madre del joven muerto no sólo como una negación de lo sucedido, sino sobre todo como des-jerarquización de la vida y, al mismo tiempo, como una forma de restar gravedad a la muerte de su hijo. Para el Estado, para la justicia estatal su vida valía poco y eso se evidenciaba en el monto de las penas de los policías. Intentando calmarla, algunos/as activistas que las acompañaban ensayaron una respuesta rápida, "si dejamos que sean ellos (los jueces) los que digan cuánto vale la vida de Jonatan, ellos ganan y nosotros perdemos. Gracias a todo lo que ustedes hicieron desde su muerte, todos sabemos quién era Jonatan, cómo y quiénes lo mataron y cuánto valía su vida”. Esa afirmación pareció calmarla, al menos parcialmente.

Esa pregunta y esa respuesta ensayada rápidamente para intentar apaciguar su sufrimiento permiten colocar ciertos interrogantes, que resultan significativos para pensar formas, sentidos, valores y prácticas ligados a las luchas por la justicia y el reconocimiento de la vulneración de derechos. ¿Quién está legitimado socialmente para establecer el valor de la vida y de la muerte? ¿Cómo se construye esa legitimidad? ¿Esa potestad recae única y exclusivamente en el Estado, en las agencias estatales encargadas de administrar justicia? ¿Existen otros actores sociales $\mathrm{u}$ otras arenas donde construir y/o disputar esas valoraciones y sentidos? ¿Existen otras formas de politizar las muertes que exceden la arena jurídica?

En este artículo ensayamos algunas respuestas a esos interrogantes a partir de reconstruir, desde una perspectiva etnográfica, una intervención teatral realizada por familiares, amigos/as del joven muerto, artistas locales, activistas y militantes de distintas organizaciones sociales, que integró el repertorio de protesta con motivo de la muerte de Jonatan Herrera; de la cual, por nuestra cercanía y vínculo construido con la familia del joven, participamos desde su inicio, colaborando en el diseño, en la puesta en escena y en la redacción del libreto, entre otras acciones, a partir de las cuales somos observadoras privilegiadas de todo el proceso que aquí se analiza.

Unos meses antes que se iniciara el juicio oral, Julieta, su hermana, propuso realizar una obra de teatro en la que participarían hermanos/as, primos/as y amigos/as de Jonatan. "Queremos que se sepa quién era Jonatan, cómo murió y todo lo que nos costó la búsqueda de justicia” explicó Julieta, en los primeros 
encuentros para diseñar dicha intervención. A partir de esa propuesta nos reunimos junto a actores, actrices, directores/as de teatro y cine, músicos/as de la ciudad, familiares y amigos/as, militantes y activistas que venían acompañando la causa desde un primer momento; y comenzamos a diseñar y ensayar la obra de teatro, que se estrenó frente al edificio de tribunales provinciales el primer día del juicio oral; y se volvió a realizar en distintas oportunidades.

Partimos de la hipótesis que dicha intervención se constituyó en una instancia relevante de politización de la muerte. Retomamos este concepto de Pita (2010), quien señala cómo las distintas formas de intervención, activismo y protesta de los familiares de jóvenes muertos por la policía implican la politización de muertes (políticas) de vidas no políticas, en tanto resistencia última al poder de matar del Estado $^{2}$. En este sentido, consideramos que la intervención teatral se constituyó en una instancia relevante de politización en tanto significó una forma de reasignación de humanidad al joven asesinado, a partir de la recomposición de su biografía en tanto vida digna de ser vivida y la consiguiente construcción de una memoria social posible sobre su vida y su muerte; porque implicó una forma de construcción de verdad y justicia que excedió la arena jurídica y, en tanto, supuso una intensa y creativa implicación corporal por parte de sus familiares y amigos/as.

El trabajo está organizado en tres partes. En primer lugar, se describe la muerte de Jonatan y como ese suceso a partir del activismo de familiares, amigos/as, querellantes y organizaciones sociales se constituyó en el "caso Jonatan Herrera”. En el segundo apartado, se reconstruye la intervención teatral "Yo sabía a Jonatan Herrera lo mató la policía". En la tercera parte, se analiza cómo dicha intervención se constituyó en una instancia relevante de politización de la muerte (PITA, 2010) y se vincula esa acción con las diferentes matrices de las políticas visuales del movimiento de derechos humanos en Argentina (LONGONI, 2010). Finalmente, recapitulamos los asuntos centrales del trabajo para dar curso a las reflexiones finales.

\footnotetext{
2 Pita sostiene que las muertes producidas por policías son políticas -en tanto expresan la pura sujeción al poder soberano y su poder de dar muerte-; de vidas no políticas -en tanto no han sido vidas dedicadas a la resistencia política-; y que el activismo, la protesta y la impugnación de los familiares de los muertos; es decir, su trabajo de politización: "consiste en el movimiento de develar su estado de nuda vida, sometida, reducida al despojo y a la pura entrega al poder soberano, es decir, su estado de exclusión incluida y la resistencia a permanecer en él" (PITA, 2010, p. 22); rechazando así su condición de "matables" (AGAMBEN, 1998).
} 


\section{PRIMERA PARTE: LA MUERTE DE JONATAN Y LA CONSTRUCCIÓN DEL CASO HERRERA}

La tarde del cuatro de enero del año 2015, Jonatan Herrera -un joven de un barrio popular de la zona sur de la ciudad de Rosario, Argentina-, mientras se encontraba lavando su auto en la vereda de su casa, junto a un primo y un hermano, fue herido por agentes de la -por entonces- recientemente creada Policía de Acción Táctica (PAT) y por policías del Comando Radioeléctrico (CRE), ambas fuerzas pertenecientes a la policía de la provincia de Santa Fe. Según el relato de familiares y algunos testigos, ese día, agentes de la PAT que viajaban en un colectivo del transporte urbano de pasajeros, observaron a policías del CRE perseguir a un joven -acusado de haber realizado un robo en una juguetería. Algunos/as de los/as policías decidieron detener el colectivo, descender y sumarse a la persecución, disparando sus armas de fuego reglamentarias en esa dirección, en la cual también se encontraban Jonatan, su primo y su hermano. El joven perseguido ya había sido reducido por agentes del CRE cuando se inició la balacera contra Jonatan y los dos jóvenes que lo acompañaban, de la que participaron policías de ambas fuerzas. Jonatan recibió tres disparos de armas de fuego y horas después falleció en un hospital de la ciudad. Murió como consecuencia del impacto en su cuerpo de tres de los más de cincuenta disparos emitidos por una suerte de "pelotón de fusilamiento", tal como fue descripto en más de una oportunidad por sus familiares y testigos de lo sucedido.

María Elena, su mamá, y Julieta, su hermana, protagonizaron, junto a demás familiares y amigos/as, el reclamo de justicia por la muerte del joven. Desde el día de la muerte se las vio hablando con la prensa local para rebatir la versión policial que intentaba presentar lo sucedido como un "enfrentamiento", organizando manifestaciones en el barrio, recorriendo los pasillos de tribunales, asistiendo a cada una de las audiencias de la causa. A su vez, diversos

\footnotetext{
Diversos estudios en el contexto local han relevado que resulta ser una práctica policial frecuente en estos casos; es decir, los propios policías involucrados en la muerte son quienes están encargados de realizar las primeras actuaciones y suelen construir una versión oficial de los hechos para intentar; por un lado, revestir de legalidad una práctica ilegal (CELS, 2018); y al mismo tiempo, dotarla de cierta legitimidad. En este sentido, suelen describir lo sucedido como un "enfrentamiento" entre policías y "delincuentes".
} 
actores sociales -activistas, militantes de organizaciones políticas, sociales y derechos humanos- colaboraron en el sinuoso proceso de construcción de esa muerte como un caso de "violencia institucional"4; es decir, inscribirlo en una serie que permita el reclamo de la responsabilidad estatal por lo sucedido 5 .

En el contexto argentino, de manera similar a otros países de la región, la violencia policial se concentra sobre algunos grupos poblacionales que revisten determinadas características en relación principalmente a clase, género, raza ${ }^{6}$, edad y lugar de residencia ${ }^{7}$. Es decir, los jóvenes muertos por la policía son en su gran mayoría varones, pobres, que viven en barrios populares. Al mismo tiempo, suelen aparecer caracterizados por diversos actores sociales -la propia policía, funcionarios/as judiciales, medios de comunicación y amplios sectores sociales - como "delincuentes", en contraposición a jóvenes "decentes" "que trabajan y estudian"; y los barrios en los que habitan como lugares que concentran altos niveles de peligrosidad; colaborando, de este modo, a cierta legitimación de estas muertes y del accionar policial, ya que se presentan en términos de acciones defensivas en contextos bélicos, de "guerra contra la delincuencia".

En ese sinuoso proceso de búsqueda de justicia, muchas de las acciones, además de cuestionar el accionar policial, en términos de que no fue un "enfrentamiento" -sino que hubo un uso ilegal de la fuerza-, están dirigidas a problematizar la caracterización inicial de la víctima construida en la versión policial y reproducida en el espacio judicial. Es decir, intentar "limpiar" la moralidad de la víctima para disputar su pertenencia a un "otro peligroso", a un "enemigo social" al que está "justificado" matar.

Al poco tiempo, el fiscal a cargo de la investigación judicial solicitó imputar a cuatro policías pertenecientes a la PAT por la muerte del joven; uno de ellos por el delito de homicidio y los tres restantes por tentativa de homicidio. Meses

\footnotetext{
4 Para un mayor desarrollo de esta categoría ver Pita (2017).

5 Un análisis contrastativo de estos procesos en el contexto argentino y brasileño se puede ver en Eilbaum y Medeiros (2015).

6 En Argentina los dispositivos de racialización en relación al significante negro no operan solamente sobre afro-descendientes y/o inmigrantes africanos, sino también sobre poblaciones originarias y mestizas, produciendo una ampliación de noción de negritud que abarca una diversidad de poblaciones, Gatto (2016).

7 Se pueden encontrar datos sobre muertes producidas por la policía en CELS/UNR (2017) y CELS (2018).
} 
después, los abogados que primeramente representaban a la familia Herrera, junto al fiscal interviniente intentaron convencer a María Elena y Julieta de concluir la investigación judicial y atribuir responsabilidades por la muerte de Jonatan a través de un juicio abreviado ${ }^{8}$ para tres de los imputados. El acuerdo implicaba modificar la calificación legal inicial a una menos gravosa.

Frente a esta situación la familia Herrera, decidió revocar el poder que otorgaba representación legal a sus primeros abogados -ligados al "mundo penal" - y nombró nuevas abogadas querellantes -ligadas ahora sí al "mundo de los derechos humanos" y pertenecientes a dos organizaciones sociales. A partir de ahí la causa comenzó a tener una mayor visibilidad pública, a través de la conformación de una Multisectorial denominada "Justicia por Jonatan Herrera", integrada por familiares, organizaciones sociales, políticas y de derechos humanos locales.

Casi un año y medio después de ocurrida la muerte, a partir de nuevas pericias ordenadas por la fiscalía a cargo de la investigación judicial, una policía del CRE fue detenida e imputada de ser la autora de uno de los disparos que recibió Jonatan. En el mes de marzo del año 2017, se inició el juicio oral y público contra los/as cinco policías imputados/as y acusados/as. Dicho juicio tuvo amplia cobertura de los medios de comunicación locales. Además, durante todo el trámite los familiares del joven contaron con el acompañamiento de activistas y militantes de la Multisectorial Contra la Violencia Institucional, una organización de derechos humanos creada en la ciudad de Rosario en el año 2016, compuesta por organizaciones políticas, sociales, sindicales, académicas, de derechos humanos y culturales. También acompañaron a la familia personalidades del "mundo de los derechos humanos" y de la política local.

Durante el juicio quedó evidenciada la responsabilidad policial; no obstante, en abril del mismo año, los jueces de primera instancia dictaron una sentencia que, como mencionamos, fue rechazada e impugnada por entenderse

\footnotetext{
8 Instituto procesal que permite una negociación entre fiscal y defensor, por medio del cual, frente a las pruebas recabadas, el defensor le propone al acusado reconocer su responsabilidad, evitando someterse a una instancia pública de juzgamiento y reducir su pena, Renoldi (2017).
} 
que la misma atentaba gravemente contra la vigencia efectiva de los derechos humanos y consagraba impunidad ${ }^{9}$.

La muerte de Jonatan a través del activismo de familiares, querellantes y organizaciones sociales, políticas y de derechos humanos se convirtió en un caso paradigmático, que permitió evidenciar prácticas policiales de uso de la fuerza mucho más extendidas. Es decir, se trata de casos que ilustran patrones problemáticos de uso de la fuerza policial (TISCORNIA, 2008). En tal sentido, constituyen ejemplos de un fenómeno más general, al decir de Tiscornia (2008, p. 3):

estas muertes acontecimientos son sólo un ejemplo de un fenómeno más vasto, de un lenguaje de violencia local que más que hechos extraordinarios, eran parte de un complejo proceso de legitimación armado sobre saberes policiales, sobre normas jurídicas, sobre costumbres institucionales.

El caso Jonatan Herrera acreditó prácticas policiales violentas, especialmente sobre jóvenes de sectores populares. Dejó en evidencia, además, prácticas policiales en la investigación - como la alteración del lugar del hecho-, a fin de lograr la impunidad de los/as policías involucrados/as. También evidenció deficiencias en la posterior investigación fiscal. No obstante, no obtuvo el desenlace judicial esperado por familiares, militantes y activistas.

\section{SEGUNDA PARTE: LA MUERTE DE JONATAN Y LA INTERVENCIÓN TEATRAL “YO SABÍA A JONATAN LA MATÓ LA POLICÍA"}

La intervención teatral retoma una expresión típica de la semiología manifestante (FILLIEULE; TARTAKOWSKY, 2015) contra la violencia

\footnotetext{
9 La policía del CRE fue absuelta por unanimidad. El agente de la PAT acusado de homicidio calificado fue condenado a seis años y seis meses de prisión, por homicidio culposo. Los tres agentes de la PAT restantes fueron condenados a tres años y ocho meses por abuso de armas agravado. Todos los policías condenados se encuentran actualmente en libertad, mientras que el joven acusado de robar la juguetería, que dio origen a la persecución policial, fue condenado a seis años de prisión por el delito de robo y al momento de escritura de este trabajo permanece privado de su libertad.
} 
institucional en democracia, sintagma que se populariza en Argentina, en el proceso de búsqueda de justicia por el asesinato de Walter Bulacio ${ }^{10}$. Esta intervención se realizó en cinco oportunidades durante el año 2017 y adoptó diferentes versiones: el 1 de marzo se estrenó frente a tribunales provinciales, día en que comenzó el juicio oral y público; el 6 de abril se repitió, en el mismo sitio, cuando se dictó la sentencia a los/as policías involucrados/as; el 8 de mayo se hizo en el Museo de la Memoria de la ciudad, con motivo de conmemorarse el Día Nacional de Lucha Contra la Violencia Institucional ${ }^{11}$; el 3 de agosto se reiteró al iniciar la audiencia de apelación a la sentencia de primera instancia; y, finalmente, se llevó a cabo durante una vigilia realizada el 4 de octubre, a la espera del fallo del tribunal de segunda instancia.

La primera versión de la obra que tuvo cita en dos oportunidades (el 1 de marzo y el 6 de abril) comienza con un relato de Julieta quien recupera distintas facetas de la vida de su hermano (sus gustos musicales, su pasión por el fútbol, sus creencias religiosas, sus aspiraciones como estudiante y la relación con su propio cuerpo). Aristas de una vitalidad obstruida (ya que son relatadas en pasado), representadas por sus hermanos que desdoblan a Jonatan en varios personajes. Una vez que cada uno de ellos es puesto en acto y sellado con el grito "Jonatan", la escena se interrumpe abruptamente con la recreación del momento de la ejecución. Una veintena de policías, interpretados/as por actores y actrices del circuito teatral de la ciudad, familiares y amigos/as de Jonatan, ingresan simulando la persecución policial que antecede la ejecución. Una brutal cacería, gritos, golpes, corridas y, una vez reducido el otro joven perseguido (que interpreta al joven acusado de robar la juguetería), los/ as agentes, dispuestos en pelotón de fusilamiento, acribillan a Jonatan; a cada uno de los Jonatan, a cada una de sus líneas vitales. Luego se entrometen en el

\footnotetext{
${ }^{10}$ Se trató de un joven que falleció en una dependencia policial, luego de haber sido detenido en la ciudad de Buenos Aires y como consecuencia de haber recibido golpes de parte de la policía, en el año 1991, para más detalles ver Tiscornia (2008).

${ }^{11}$ Este día fue instituido por ley, en el año 2013, para recordar las violaciones a los derechos humanos producidas por las policías y fuerzas de seguridad en democracia; y con el propósito de promover políticas públicas de seguridad respetuosas de los derechos humanos. Se escogió el 8 de mayo para conmemorar la denominada "Masacre de Ingeniero Bunge" en la que tres jóvenes fueron asesinados por la policía de la provincia de Buenos Aires, en el año 1987.
} 
público, amenazan y amedrantan a los/as espectadores/as. Limpian la escena, arrastran, cargan y apilan todos los cuerpos, todos los Jonatan.

Posteriormente, una nutrida columna de manifestantes, representada por su madre, otros familiares y por militantes de diversas organizaciones ingresa a la escena coreando "Yo sabía, yo sabía que a Jonatan Herrera lo mató la policía. ¡Asesina!". Des-apilan uno a uno los cuerpos, los levantan y los suman a la columna. Solo uno de los Jonatan camina en dirección a tres actores que interpretan a la corporación judicial. Una actriz que encarna a la Justicia, vestida de blanco y con una venda que cubre solo uno de sus ojos, vuelve a dispararle al Jonatan que se acerca a paso cansino hacia ella. Julieta, que continúa relatando cada uno de los acontecimientos, lo levanta, se abrazan. Luego se acerca a la actriz que representa a la Justicia, le acomoda la venda logrando tapar ambos ojos y grita "Exigimos que se haga justicia". El cántico de los/as manifestantes vuelve a oírse para culminar la intervención que dura apenas cinco minutos.

Esta primera pieza teatral experimentó algunas transformaciones acordes al avance y los resultados del proceso judicial, generando dos nuevas versiones. Así, para la presentación que se realizó el 8 de mayo, un mes después de conocida la sentencia, se incorporó, en las escenas finales de la intervención un audio, que fue grabado en vivo durante el juicio, en el que se escucha la decisión dictada por los jueces de primera instancia. En las otras dos ocasiones en las que se realizó, con motivo de la audiencia ante el tribunal de segunda instancia, se incorporaron escenas que dieron lugar a una tercera versión. Se adhirió una secuencia entre tres personajes que representan a los jueces y otra entre la madre de Jonatan y la actriz que encarna a la Justicia.

Así, sobre el final de la obra se desarrolla una escena en la que tres actores, caracterizados con indumentaria comúnmente utilizada por los/as integrantes del Poder Judicial y con cabezas gigantes de cartapesta que caricaturizan los rostros de los jueces de primera instancia, parodian la impunidad judicial y política. Mientras se oye una melodía circense, dramatizan una suerte de orgía entre ellos y la actriz que representa a la justicia, en la que ésta última experimenta situaciones de desagrado, se siente intimidada, asustada, 
incluso violentada y manoseada por los actores que representan a los jueces. Finalmente, en la escena siguiente, la madre de Jonatan auxilia a la justicia, le acomoda la ropa, la calma y sostiene una conversación íntima, en voz baja, casi inaudible, que culmina en un abrazo entre ambas. A los ojos del público, transcurre una suerte de acuerdo, de pacto, de entendimiento amoroso entre esas dos mujeres. Casi en secreto algo traman, no sabemos qué. Una cofradía.

\section{TERCERA PARTE: LA MUERTE DE JONATAN, LA PRODUCCIÓN DE MEMORIA, VERDAD Y JUSTICIA}

\section{Memoria: ¿quién era Jonatan Herrera?}

Figura 1: Intervención teatral “Yo sabía a Jonatan lo mató la política”.

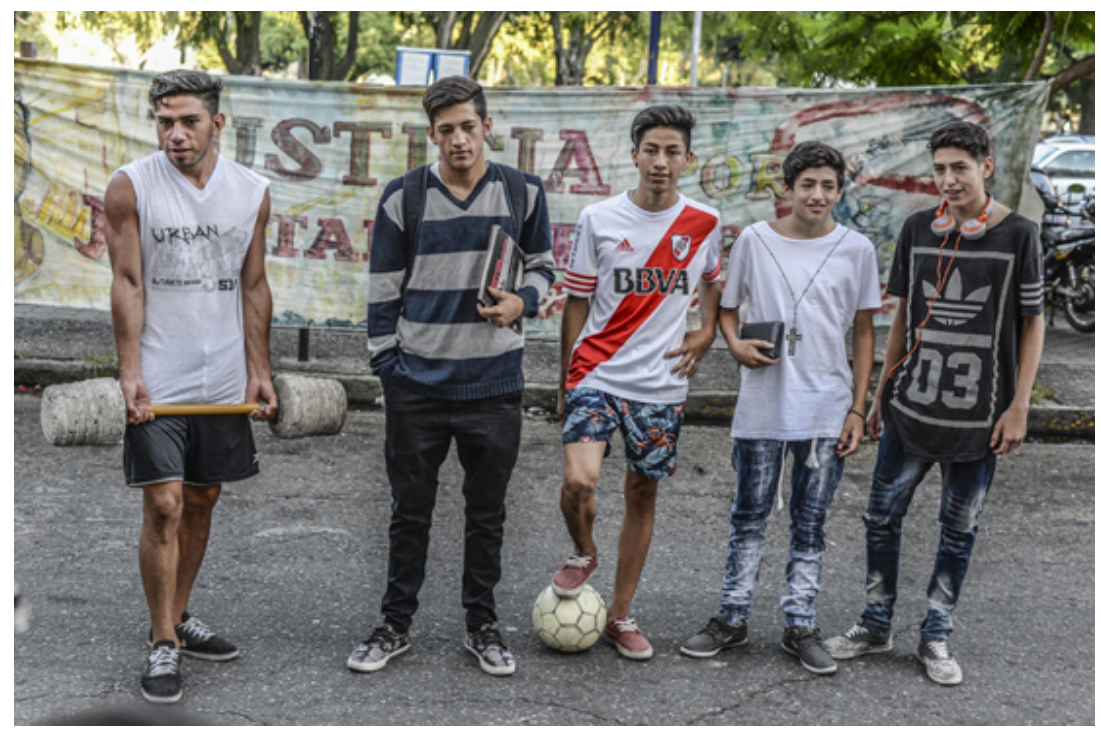

Fuente: Diego Stortoni.

La trama argumental de la intervención comienza con escenas destinadas a recomponer la trayectoria vital del joven Jonatan Herrera, representando distintas facetas de su biografía íntima a través del cuerpo de sus propios hermanos que encarnan a distintos Jonatan, sus diferentes dimensiones vitales; disputando asílas 
imágenes sociales hegemónicas construidas sobre estos jóvenes y sus muertes a las que hicimos referencia. Vista desde esta perspectiva, resulta inevitable al menos mencionar el delicado diálogo que esta intervención sostiene con la primera matriz de las políticas visuales y performáticas del movimiento de derechos humanos en Argentina (LONGONI, 2010). La misma se configuró principalmente por los múltiples usos de las fotografías de sus hijos/as que hicieron las Madres de Plaza de Mayo $^{12}$, recurso que, por lo demás, también tuvo un fuerte protagonismo en otras acciones gráficas de este repertorio. Esta fase de la obra abre, asimismo, otro itinerario difícil de eludir con El Siluetazo ${ }^{13}$. Más precisamente, con la ética implícita en su modo de producción, a saber, el acto de prestar u ofrendar el propio cuerpo para presentificar a ese otro cuerpo ausentado, asesinado o desaparecido; aunque aquí no ya como molde, sino en carne viva. Se ancla en la primera matriz porque focaliza en la figura de la víctima, en la biografía y la vitalidad de Jonatan, aspirando a revertir la concepción de este joven como "matable", como una vida anonimizada, sin biografía ni historia, que merece morir y cuya muerte no debe ser llorada ni juzgada. Re-asigna, de este modo, calidad humana a una vida que intentó ser privada de su condición de tal. De algún modo, le restituye humanidad (PITA, 2010). Corporeiza a ese joven desplazándolo de su condición cifrada, de un número más que integra la cuenta de personas víctimas de violencia policial en su extremo más letal. Restituye actitudes, gustos, gestos, voces a Jonatan, reponiendo su densidad personal y familiar en una narración identitaria que, a su vez, delineó una figura de víctima universalizable, que puede ser metonimizada por el resto del cuerpo social, en tanto parte de ese todo.

\footnotetext{
12 Se trata del colectivo de mujeres madres de víctimas de la última dictadura cívico-militar argentina (1976-1983) que comenzaron a agruparse y reunirse en Buenos Aires en el año 1977, con el fin de exigir la aparición con vida de sus hijos/as detenidos/as desaparecidos/as durante dicho régimen dictatorial y, posteriormente, con la intención exigir justicia por los delitos de lesa humanidad cometidos. Objetivos a los que posteriormente, y luego de su constitución como organismo de derechos humanos, sumaron otros vinculados a la propagación de políticas de la memoria, la educación en temáticas afines, entre otros.

13 La denominación "Siluetazo" corresponde a la acción estético-política realizada por primera vez en la III Marcha de la Resistencia convocada por las Madres de Plaza de Mayo en 1983 que consistió en dibujar sobre papeles siluetas; es decir, trazar la forma vacía de un cuerpo a escala natural, utilizando como molde otros cuerpos humanos, que luego fueron pegados en los muros de la ciudad. La iniciativa partió de tres artistas visuales (Aguerreberry, Flores y Kexel) y en su definición y concreción participaron, además de las Madres, las Abuelas de Plaza de Mayo y otros organismos. También con este nombre se conocen dos ediciones ulteriores de esta acción consumadas en diciembre de 1983 y marzo de 1984. Posteriormente, se realizaron otras acciones estético-políticas con esta técnica, en otros soportes (calle, paredes, etc.), con otros actores, espacios y tiempos que se han conocido también como "silueteadas".
} 
Lo que se estimula más allá de la asimilación o reconocimiento de la condición de víctima, es la identificación social con esa vida vivible así como a la responsabilidad comunitaria porque ya no podrá ser vivida. Por consiguiente, la implicación común en muertes y en vidas que no son las nuestras. Como sostiene Butler "una vida concreta no puede aprehenderse como dañada o perdida si antes no es aprehendida como viva. Si ciertas vidas no se califican como vidas o, desde el principio, no son concebibles como vidas dentro de ciertos marcos epistemológicos, tales vidas nunca se considerarán vividas ni perdidas en el sentido pleno de ambas palabras" (BUTLER, 2010, p. 13). De este modo, la primera parte de la intervención teatral repone la potencia vital de Jonatan, las líneas de vida obstruidas con su muerte. $Y$, en un segundo movimiento, revierte su concepción de "matable". Una vida (y una muerte ahora) que importa ${ }^{14}$.

La consideración en torno a la condición de "matables" o merecedores de muerte de ciertos jóvenes caracterizados como "delincuentes", trae aparejada una distribución desigual de quienes tienen derecho a ser rememorados, de quienes merecen duelo (privado o público) y, también, supone una asignación diferencial de las vidas capaces de suscitar memoria -más allá del recuerdo- social o comunitaria. Este primer tramo de la intervención interpela también, entonces, la posibilidad de construir una memoria colectiva sobre Jonatan. Memoria que, en principio, necesitará -como veremos de inmediato- de la posibilidad de enunciar otra "verdad", la propia, sobre lo sucedido con su vida. Y, como correlato, requerirá de la construcción de un poder político de verdad (JELIN, 2007); es decir, de un lugar válido y legítimo de enunciación por parte de sus familiares, amigos/as y el colectivo manifestante que lleva adelante el proceso político de construcción de justicia ${ }^{15}$.

\footnotetext{
14 Esta frase "vidas que importan" remite a activismos vinculados a la violencia policial presentes en otros contextos. Particularmente, resulta ineludible la referencia al Movimiento "Black LivesMatter" (TAYLOR, 2017), que tiene un rol central en el desarrollo del nuevo "activismo negro" en los últimos años AAVV (2016). Si bien no identificamos relaciones y/o conexiones explícitas con el activismo local, resulta necesario resaltar las similitudes en las prácticas, símbolos y sentidos que circulan en relación a distintas experiencias ligadas a esta temática.

15 Nos resulta pertinente mencionar el rol que asigna (TAYLOR, 2000) a las acciones performáticas en la construcción de la memoria y en la elaboración del trauma. Si bien la obra teatral en sí misma puede ser entendida o tener similitudes con una performance artística, cada uno de los actos de protesta en relación a este caso puede estudiarse o entenderse como performance, tal como lo indica la autora (TAYLOR, 2012). Y en este último sentido es que destacamos la importancia de estas acciones para construir y transmitir la memoria traumática, como modo de canalizar a través de su re-escenificación el dolor y de reponer a los muertos en la escena pública, haciendo visibles sus ausencias. Y, de este modo, al mismo
} 
Configuración de una memoria que insumió e insume otros recursos simbólicos y, específicamente, artísticos que compusieron este repertorio de protesta, tales como los diversos recursos gráficos impresos con su rostro (pancartas, flyers, volantes), banderas en las que flameó su imagen, murales y remeras que, con diferentes diseños, conformaron una prenda clave en la elaboración de las comparecencias (DIDI-HUBERMAN, 2014); es decir, de los modos de aparecer públicos de sus familiares y amigos/as.

Esta estrategia subraya el vínculo íntimo, biológico entre quienes protagonizan la intervención (o visten la remera) y el joven víctima, al igual que las "fotos en pecho" de las Madres de Plaza de Mayo resaltaban, en los primeros tiempos, el vínculo entre quien la portaba y el desaparecido. Reivindicación que fue motivo de arduas discusiones con posturas que apostaban a la socialización de ese lazo familiar y a la construcción de dispositivos visuales colectivos (LONGONI, 2010). Y que, más allá de las discusiones, no es excluyente, sino tal vez un primer paso en la ansiada construcción de una memoria social sobre estas historias vitales que impugna la des-jerarquización estatal y social sobre esa vida y esa muerte.

\section{La otra verdad: ¿qué cuerpos pueden pronunciarla?}

Figura 2 - Intervención teatral “Yo sabía a Jonatan lo mató la política”.

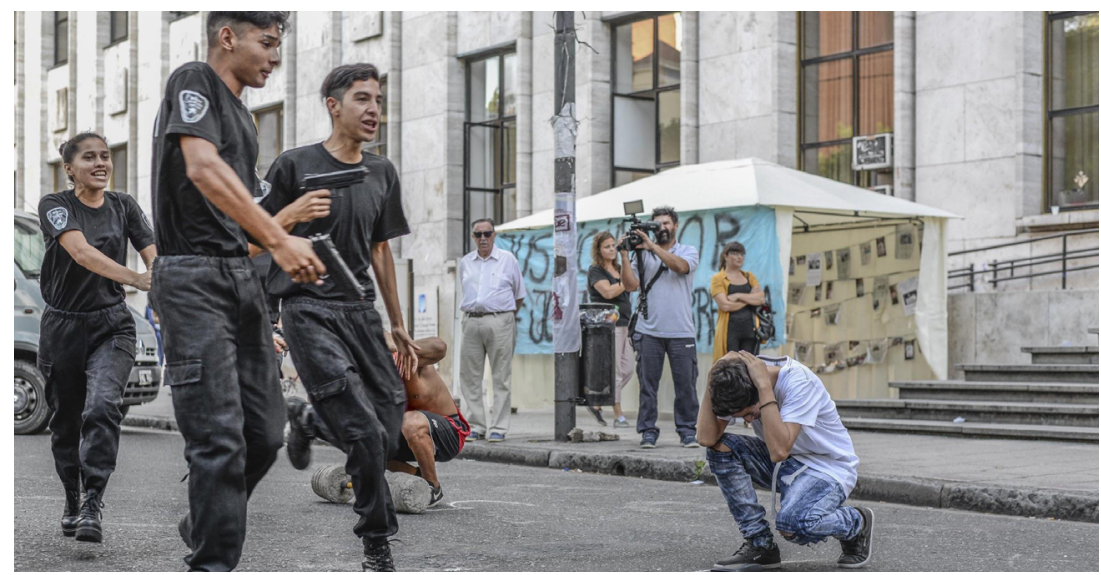

Fonte: Fotografía de Diego Stortoni.

tiempo que logran la atención pública adquieren una función restauradora y permiten que el trauma devenga en algo transmisible, algo soportable y políticamente eficaz (TAYLOR, 2000). 
"La capacidad de ser llorado es un presupuesto para toda vida que importe" (BUTLER, 2010: 32). Es un futuro anterior instalado como condición de esa vida, de un ser que en tanto vivo está expuesto a la no-vida desde el principio (BUTLER, 2010). ¿Qué vidas son sufridas?, ¿quiénes tienen derecho a sufrir?, ¿ por qué sufren quienes sufren?, ¿qué sucedió con esos cuerpos próximos? son preguntas que configuran una segunda zona de la intervención, aquella que se inicia con el ingreso abrupto y desaforado de una manada policial que recrea la forma en que Jonatan fue asesinado, la necro-teatralidad (DIÉGUEZ, 2013) desplegada en su fusilamiento, las formas de dar muerte a esas vidas, construyendo de ese modo, otro relato, otra versión a la que, tal como mencionamos, jurídica, social y mediáticamente suele prefigurarse de inmediato criminalizando a los jóvenes ante estos casos.

Estas escenas son protagonizadas por actores y también por sus propios familiares y amigos/as recargando la intensidad corporal que a partir del primer minuto porta esta intervención. Estos cuerpos representan también a los victimarios evidenciando una modulación de esa particular ética del cuerpo legada por los familiares de víctimas de violencias de Estado, que en este caso adquirió una especial densidad trágica.

Figura 3 - Intervención teatral “Yo sabía a Jonatan lo mató la política”.

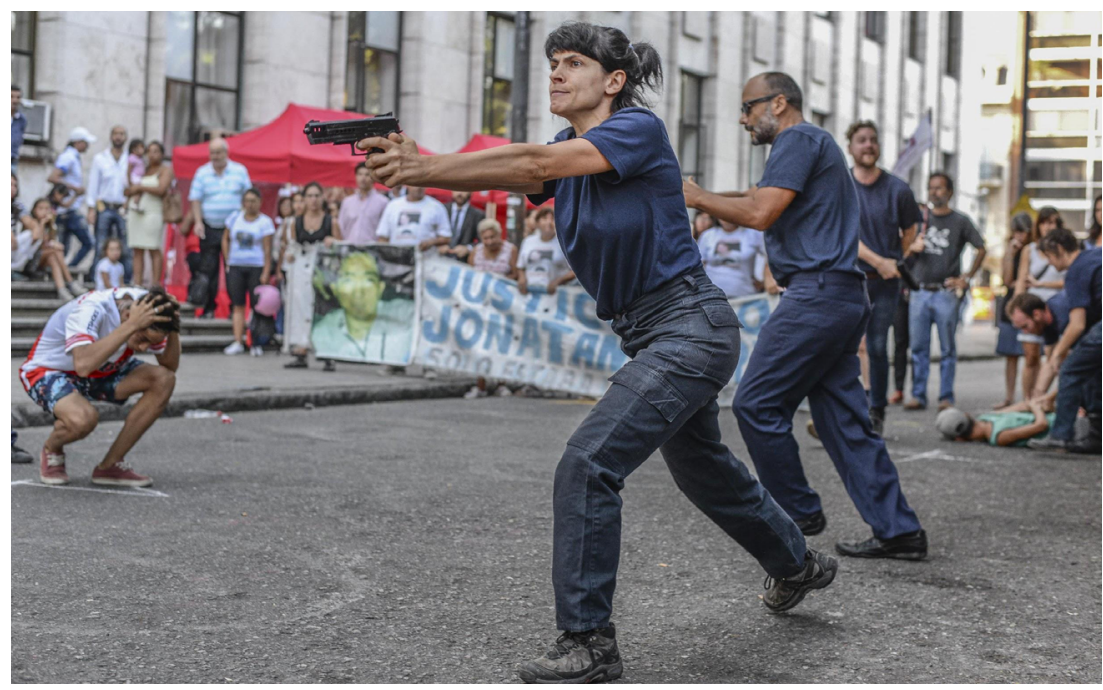

Fonte: Fotografía de Diego Stortoni. 
A simple vista, esta zona de la intervención complejiza la vinculación que hicimos en el apartado anterior, ya que se liga con una tercera matriz de las políticas visuales y performáticas que inauguraron los H.I.J.O.S. ${ }^{16}$ a partir de la gramática de los escraches (LONGONI, 2010) en la que además de señalar públicamente; es decir, des-ocultar de la trama social a los miembros de las Fuerzas Armadas y de Seguridad responsables de los crímenes de lesa humanidad, mostraban los modos de hacer de la violencia de Estado. La inscripción parcial en esta tercera matriz es subrayada, nuevamente, en la última modulación de la intervención teatral, a la que volveremos, cuando actores con cabezudos encarnan a los jueces y parodian escenas de impunidad y corrupción judicial.

Los familiares y amigos/as representan a los victimarios y también muestran en la escena pública su propio dolor ${ }^{17}$. Vuelven a pasar por el propio cuerpo el momento del fusilamiento, el después inmediato, la obstrucción de esa vida y de la propia. Vuelven, ahí, en ese espacio-tiempo que oscila tensamente entre la realidad y la ficción, a llorar a sus muertos. En este sentido, la indecidibilidad de la muerte joven, su compresión obstruida y el abismo afectivo que la caracterizan, parece motivar una teatralización de las emociones adicional a la implicada en todos los ritos de despedida y tramitación de la muerte (DIÉGUEZ, 2013, p. 173). Se ejercita el derecho a las lágrimas (DIÉGUEZ, 2013, p. 173) o mejor a la exposición pública de un sufrimiento que social y culturalmente queda confinado a espacios privados, domésticos, íntimos ya que por el carácter de estas muertes (y las asignaciones valorativas socialmente vigentes sobre esas vidas), se constituyen en dolores que sólo pueden

16 H.I.J.O.S. (Hijos e hijas por la Identidad y la Justica contra el Olvido y el Silencio) es una organización de derechos humanos de Argentina fundada e integrada inicialmente por hijos/as de detenidos/as desaparecidos/as, ex presos/as políticos/as, asesinados/as y exiliados/as durante la última dictadura cívico-militar argentina (1976-1983) y a los/as que luego se sumaron otros/as militantes. Surgió en 1995 para denunciar la impunidad de los delitos de lesa humanidad cometidos durante el nombrado régimen dictatorial y exigir su condena, para lograr la restitución de la identidad de sus hermanos/as y familiares secuestrados/as y apropiados/as, así como con la intención de continuar algunos aspectos de la lucha de sus padres y madres.

17 De manera similar, las autoras Vianna y Farias, al analizar el proceso de legitimización de familiares, en especial de madres, como sujetos políticos, destacan -entre otras cuestiones- el rol significativo de la exposición pública del sufrimiento como forma de politización de las muertes producidas por la policía. Señalan, no obstante, que, si bien esa enunciación del sufrimiento permite la conexión con la lucha colectiva, no se reduce a ella; es decir, aparece un "residuo" que se expresa de manera paradójica en la afirmación de cierta imposibilidad de comunicar plenamente ese sufrimiento (VIANNA; FARIAS, 2011). 
tramitarse sanguínea y afectivamente y no en la arena pública. El derecho habilitado socialmente es a la despedida fúnebre, pero no al reconocimiento de la responsabilidad del Estado en esa muerte y la consecuente exigencia de justicia y reparación; es decir, la politización de ese dolor. Procesos que deben construirse a posteriori, paciente y colectivamente.

Figura 4 - Intervención teatral “Yo sabía a Jonatan lo mató la política”.

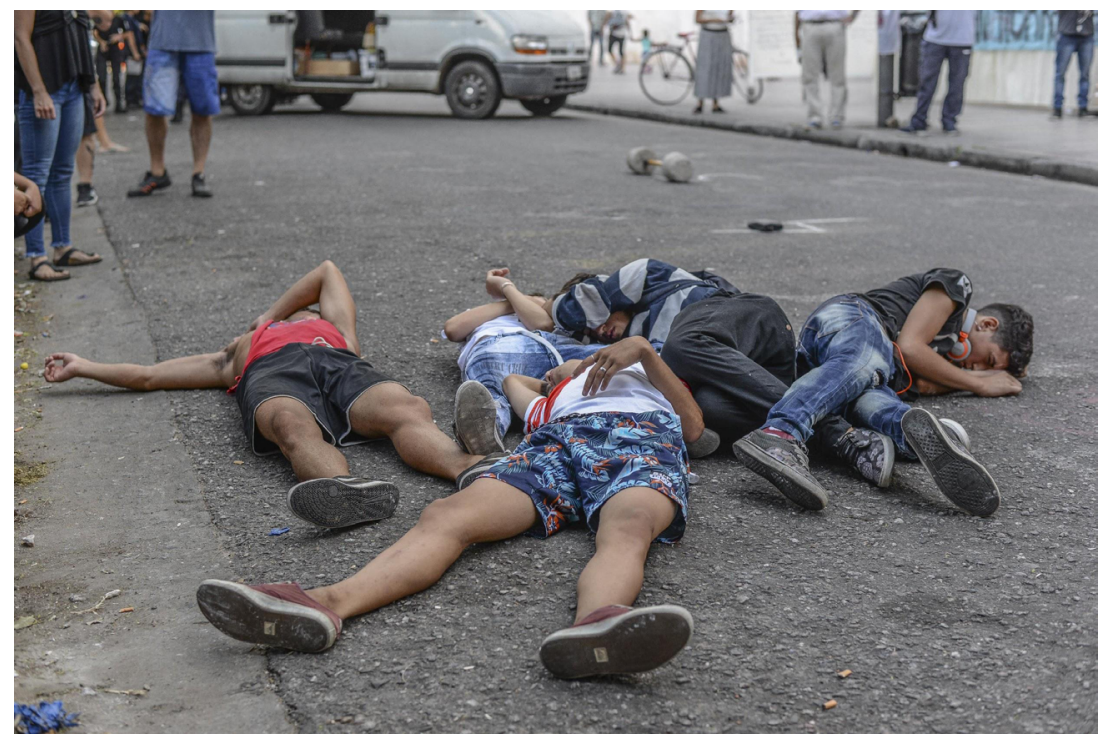

Fonte: Fotografía de Diego Stortoni.

Entonces, decíamos que la obscena visibilidad de la ejecución de Jonatan de algún modo negada por el Estado al restarle gravedad parece necesitar, para contrarrestarse, la sobre-dramaturgia, la dramaturgia de la dramaturgia, la re-escenificación de la necro-teatralidad. Ahora, en su doble, en su re-escritura escénica es reapropiada, resignificada y doblegada políticamente. Es conjurada durante toda la intervención en la que esos cuerpos ponen en movimiento potencias políticas inmovilizadas por el dolor y construyen, entonces, su poder político de verdad (JELIN, 2007). En otros términos, un lugar válido y legítimo para valorar la vida de Jonatan, para pronunciar otra verdad sobre su muerte y disputar así la versión y valoración estatal, desde un dispositivo de 
enunciación no estatal (la intervención teatral), pero que, al mismo tiempo, pretende responsabilizar al Estado. Y, en última instancia, interpelar y conmover a la comunidad que avala, habilita o simplemente es indiferente a estas formas de violencia.

\section{Justicia: búsqueda y construcción}

\section{Figura 5 - Intervención teatral “Yo sabía a Jonatan lo mató la política”.}

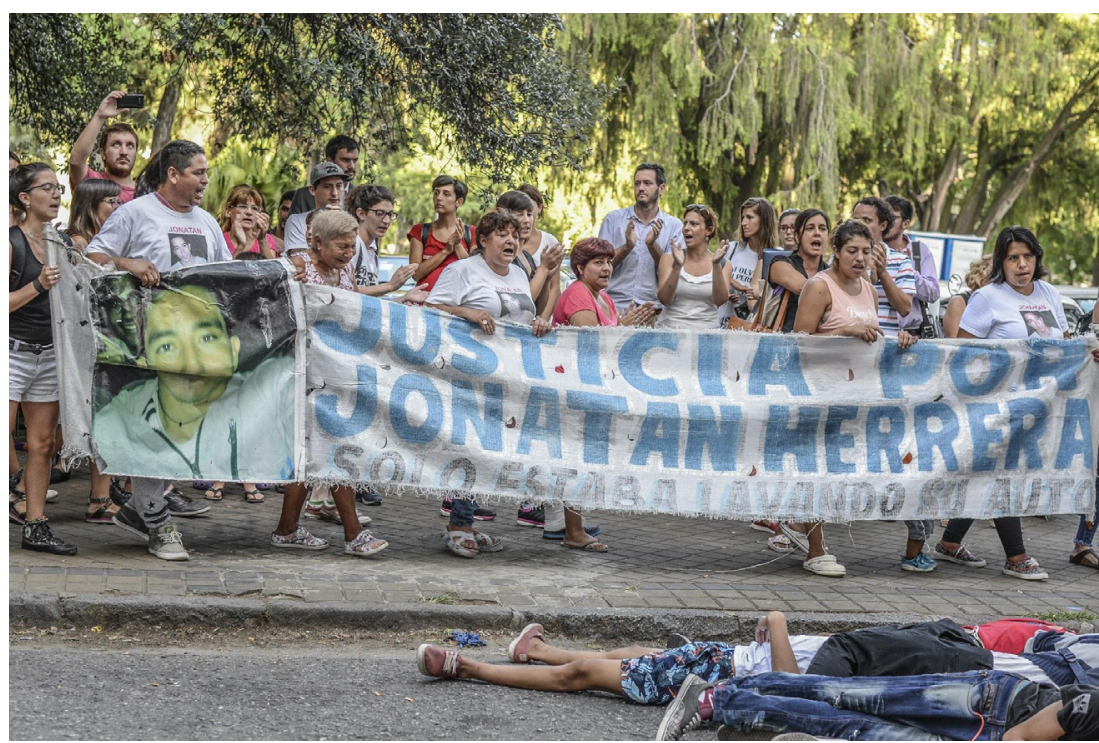

Fonte: Fotografía de Diego Stortoni.

A modo de epílogo, la primera versión de la pieza teatral contiene en su último tramo una serie de escenas que recrean el activismo de los familiares, amigos/as y diversas organizaciones sociales. Una columna de manifestantes integradas por los/as protagonistas reales de este proceso de lucha ingresa al espacio escénico portando banderas, coreando cánticos y gritando consignas típicas del activismo contra la violencia institucional. La escena tiene en primera plana, llevando la barredora que direcciona el tránsito de la manifestación, a la madre y la abuela de Jonatan. Estas mujeres, junto con otros/as, se dan 
el delicado y amoroso trabajo de desapilar los cuerpos de quienes representan las diversas aristas de la vida de Jonatan y volverlos a la vida, ponerlos de pie, uno a uno. Para que, finalmente, uno de ellos luego de haber sido rematado por la actriz que representa a la justicia estatal, se funda en un abrazo con Julieta, su hermana. Esta secuencia muestra cómo el proceso de construcción o producción de justicia excede la demanda al Estado presente en toda la obra, mostrando otras aristas del reconocimiento y la reparación más allá de su dimensión legal.

Figura 6 - Intervención teatral “Yo sabía a Jonatan lo mató la política”.

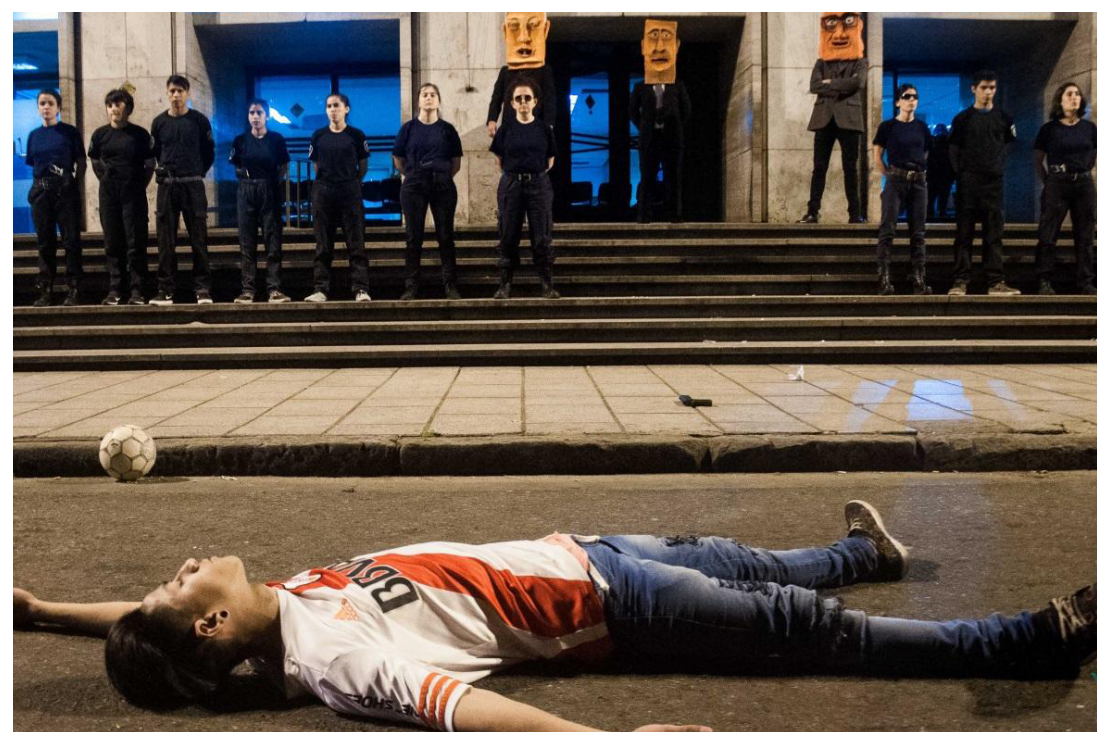

Fonte: Fotografía de Agencia Sin Cerco.

En las últimas versiones de la intervención, se denuncia la impunidad política y judicial a través de audios que relatan una sentencia que queda desencajada, disociada, que resulta absurda, casi desopilante, en relación con lo que los/as espectadores/as vieron, con el efecto de producción de verdad construido y con las percepciones y afecciones generadas en el acto convivial de ese ser-estar atravesados/as por el hecho teatral. También la impunidad se recrea con la acción protagonizada por los actores que portan los cabezudos 
y la actriz que encarna a la justicia en la que se satirizan y parodian a los miembros del Poder Judicial y se recrea una situación de manoseo y abuso de ellos hacia la justicia. Secuencia en la que, paralelamente, se cuestiona la autoridad estatal como única y exclusiva fuente legítima de reconocimiento y reparación del daño.

Esta intención había sido preanunciada en el momento que encarnan la hermana y el hermano de Jonatan cuando se abrazan, luego de que todos los cuerpos apilados de los Jonatan fueran puestos de pie, de algún modo revividos, por familiares del joven, otros familiares de jóvenes asesinados por la policía y demás activistas y militantes. Finalmente, una última escena de encuentro entre la madre de Jonatan y quien protagoniza a la justicia adhiere otra capa a ese sentido de justicia. En este momento de la obra transcurre una breve conversación e intercambio de poses y gestos. Se trama un pacto, un secreto que se performa como público pero que conserva su carácter silencioso. Condición sine qua non del secreto que se transforma en la posibilidad de dislocar la pregunta existencial con la que iniciamos este escrito.

¿Cuánto vale la vida de mi hijo?, esa pregunta abismal, sin respuesta, toma una nueva fisonomía. Se desgrana y se intenta independizar de su condición cuantitativa (en relación a la cantidad de tiempo de pena), al mismo tiempo que se re-direcciona (en relación a el/los actor/es legitimado/s para responderla). Se pretende conjugar, ahora, con otras interrogaciones que, en cierta medida, la anteceden: ¿a quién hacerle esa pregunta?; ¿quién merece ser destinatario de esa profunda interrogación, existencial, casi ontológica?, ¿a quién o a qué ungimos con esa función, capacidad, poder?

\section{ALGUNAS OBSERVACIONES FINALES}

A lo largo de este trabajo sostenemos que la intervención teatral analizada se constituyó en una instancia relevante de politización de la muerte y el dolor, en tanto significó una forma de reasignación de humanidad al joven asesinado, a partir de la recomposición de su biografía personal y familiar y 
la reposición de sus distintas líneas vitales; es decir, la figuración de una vida digna de ser vivida, de una muerte que importa y el derecho a una memoria social o comunitaria. También porque implicó una forma de construcción de verdad que conllevó, primeramente, la generación de un poder político de verdad por parte de sus familiares, amigos/as, activistas y militantes, así como la posibilidad de contar otra historia que relató lo sucedido diferenciándose de las versiones judiciales y mediáticas mediante la dramatización de la necro-teatralidad implicada en el fusilamiento de Jonatan. Es decir, una representación hiper-realista de las formas de matar de los victimarios, que supuso una intensa y creativa implicación corporal por parte de sus familiares y amigos/ as, quienes también expusieron su íntimo sufrimiento en la arena pública. Y, finalmente, porque implicó un cuestionamiento a la noción de justicia legal por los modos en que satirizó al poder judicial y político y cuestionó a la estatalidad como única instancia de producción de justicia.

En este sentido, aspiró a dislocar la pregunta que se realizara María Elena, la madre del joven asesinado, minutos después de un nuevo revés judicial. La pregunta ¿cuánto vale la vida de mi hijo? como consecuencia de una nueva des-valorización y des-jerarquización de esa vida por parte del Estado, esta vez, a través del Poder Judicial, reproduce el vínculo sólido que a menudo se traza entre la posibilidad de justicia y el Estado como único agente capaz de proveerla y, asimismo, entre la obtención de justicia y el valor de una vida. Relaciones discutidas a lo largo de la historia, en distintos momentos y por diferentes actores del movimiento de derechos humanos en el contexto argentino. El "si no hay justicia, hay escrache", arengado por los H.I.J.O.S. es quizás, en las últimas décadas, la consigna que con más contundencia abrió otros horizontes de pensabilidad sobre esos vínculos entre justicia y Estado y entre justicia legal y valoración de la vida perdida, arrancada.

Sin desconocer en absoluto la responsabilidad del Estado en la provisión de justicia legal y reparación a las víctimas de estas graves violaciones a los derechos humanos, sin negar la importancia que tiene la obtención de justicia legal para los familiares y para la sociedad en su conjunto e insistiendo en la necesidad de seguir demandando y exigiendo su cumplimiento, esta intervención -que 
se inscribe en un extenso inventario histórico de acciones estético-políticas de familiares, activistas y militantes- estimula pensar otras dimensiones necesarias a atender en estos complejos procesos de construcción de justicia.

Subraya, por una parte, la necesidad de acompañar los procesos de búsqueda de justicia legal con estrategias que a la vez que permiten politizar el dolor, generan otras posibilidades sociales y comunitarias de valoración de esas vidas que disputan el monopolio adjudicado al Estado como único actor con capacidad y poder para producirla. Y, por otra parte, motiva la indagación sobre otras zonas de la praxis política -y, específicamente, de los procesos de politización de estas muertes- como es la dimensión estético-política. Dimensión fundamental para la experimentación de esos caminos más sinuosos de configuración de otras representaciones sociales sobre esas vidas y sobre esas muertes y también para la inauguración de otras alternativas vitales para quienes quedan, para quienes siguen viviendo, más allá de su condición de víctima. En otros términos, luego - o quizás a la par- de la necesaria y trabajosa construcción de dicha condición, de esa figura de víctima que debe ser reconocida por el Estado y el cuerpo social, este tipo de prácticas estético-políticas tal vez contribuyan a evitar la solidificación en una identidad fija, resquebrajen el tránsito de una condición habitable a una identidad total (coagulación reforzada, por lo demás, en los insistentes procesos de re-victimización que deben atravesar los familiares). Es decir, quizás faciliten explorar otras posiciones de sujeto (LACLAU; MOUFFE, 2010) que motiven el despliegue de otras vidas posibles, después de esas muertes.

\section{REFERENCIAS BIBLIOGRÁFICAS}

1. BARRERA, Nicolás. Policía, territorio y discrecionalidad: una etnografía sobre la espacialidad en las prácticas policiales en la ciudad de Rosario. In: FREDERIC, Sabina et al. De armas llevar: estudios socio antropológicos de los quehaceres de policías y de las fuerzas de seguridad. La Plata: EPC, 2013.

2. BIANCIOTTO, María Laura. Repensando la homogeneidad policial: a propósito de las prácticas de comisaría y "calle" en la ciudad de rosario. Publicar, Buenos Aires, año XII, n. 17, p. 10-25, 2014. 
3. BUTLER, Judith. Marcos de guerra: las vidas lloradas. Barcelona: Paidós, 2010.

4. CENTRO DE ESTUDIOS LEGALES Y SOCIALES. Sobrecriminalizados y desprotegidos: jóvenes de sectores populares, policía y fuerzas de seguridad. Buenos Aires: CELS, 2017.

5. CENTRO DE ESTUDIOS LEGALES Y SOCIALES Muertes naturalizadas: letalidad policial sin control y sin justicia. Buenos Aires: CELS, 2018.

6. DIDI-HUBERMAN, George. Pueblos expuestos, pueblos figurantes. Buenos Aires: Manantial, 2014.

7. DIÉGUEZ, Ileana. Cuerpos sin duelo: iconografías y teatralidades del dolor. Córdoba: Escénica, 2013

8. EILBAUM Lucía; MEDEIROS, Flavia. Quando existe "violência policial"? Direitos, moralidades e ordem pública no Rio de Janeiro. Dilemas: Revista de Estudos de Conflito e Controle Social, Rio de Janeiro, v. 8, n. 3, p. 407-428, 2015.

9. FILLIEULE, Olivier; TARTAKOWSKY, Danielle. La manifestación: cuando la acción colectiva toma las calles. Buenos Aires: Siglo XXI, 2015.

10. GATTO, Ezequiel. Nuevo activismo negro: lecturas y estrategias contra el racismo en Estados Unidos. Buenos Aires: Tinta Limón, 2016a.

11. GATTO, Ezequiel. Nuevos sonidos, nuevos negros: freedom songs, soul y funk en Estados Unidos, 1955-1979. 2016. Tesis (Doctorado en Antropología) Universidad de Buenos Aires, Buenos Aires, 2016b.

12. JELIN, Elizabeth. Víctimas, familiares y ciudadanos/as: las luchas por la legitimidad de la palabra. Cadernos Pagu, Campinas, n. 29, p. 37-60, 2007.

13. LACLAU, Ernesto; MOUFFE, Chantal. Hegemonía y estrategia socialista: hacia una radicalización de la democracia. Buenos Aires: Fondo de Cultura Económica, 2010.

14. LONGONI, Ana. Arte y política. Políticas visuales del movimiento de derechos humanos dese la última dictadura: fotos, siluetas y escraches. Aletheia: Revista de la Maestría en Historia y Memoria de la FaHCE, n. 1, p. 1-23, 2010.

15. PITA, María Victoria. Formas de morir y formas de vivir: el activismo contra la violencia policial. Buenos Aires: Del Puerto, 2010.

16. PITA, María Victoria. Violencias y trabajos clasificatorios: el análisis de la noción "violencia institucional" qua categoría política local. Revista Ensambles, [S. l.], año 4, n. 7, p. 52-70, 2017.

17. RENOLDI, Brígida. Las continuidades de lo discontinuo. El trabajo policial y judicial en casos de narcotráfico en la frontera de Argentina y Paraguay. In: RENOLDI, Brígida; ÁLVAREZ, Santiago; MALDONADO ARANDA, Salvador. 
Estado, violencia y mercado: conexiones etnográficas en América Latina. Buenos Aires: Antropofagia, 2017.

18. TAYLOR, Diana. El espectáculo de la memoria: trauma, performance y política. Revista Teatro del Sur, [S. l.], v. 15, p. 33-40, 2000.

19. TAYLOR, Diana. Perfomance. Buenos Aires: Asunto Impreso Ediciones, 2012.

20. TAYLOR, Keeanga-Yamahtta. De\#Black LivesMatter a la liberación negra. Buenos Aires: Tinta Limón, 2017.

21. TILLY, Charles. Repertorios de acción contestataria en Gran Bretaña: 1758-1834. In: TRAUGOTT, Mark (comp.). Protesta social: repertorios y ciclos de la acción colectiva. Barcelona: Hacer, 2002. p. 1-17.

22. TISCORNIA, Sofía. Activismos de los derechos humanos y burocracias estatales: el caso Walter Bulacio. Buenos Aires: Del Puerto, 2008.

23. VIANNA, Adriana; FARIAS, Juliana. A guerra das mães: dor e política em situações de violência institucional. Cadernos Pagu, São Paulo, n. 37, p. 79-116, 2011. 